\title{
"Atropisomeric" Drugs: Basic Concept and Example of Application to Drug Development
}

\author{
Robert B. Raffa1,2,3, Joseph V. Pergolizzi Jr.1,4, Robert Taylor Jr.4 \\ ${ }^{1}$ Neumentum Inc., Palo Alto, CA, USA \\ ${ }^{2}$ College of Pharmacy, University of Arizona, Tucson, AZ, USA \\ ${ }^{3}$ School of Pharmacy, Temple University, Philadelphia, PA, USA \\ ${ }^{4}$ NEMA Research Inc., Naples, FL, USA \\ Email: robert.raffa@temple.edu
}

How to cite this paper: Raffa, R.B., Pergolizzi Jr., J.V. and Taylor Jr., R. (2020) "Atropisomeric" Drugs: Basic Concept and Example of Application to Drug Development. Pharmacology \& Pharmacy, 11, 1-8. https://doi.org/10.4236/pp.2020.111001

Received: December 10, 2019

Accepted: January 4, 2020

Published: January 7, 2020

Copyright ( $\odot 2020$ by author(s) and Scientific Research Publishing Inc. This work is licensed under the Creative Commons Attribution International License (CC BY 4.0).

http://creativecommons.org/licenses/by/4.0/

\begin{abstract}
Many therapeutic drugs are racemates; i.e. they are chiral molecules consisting of "left"- and "right-handed" enantiomers (stereoisomers that are mirror images of each other, and are non-superimposable). In some cases, both enantiomers of the drug contribute to some extent (or equally) to the therapeutic effect; in other cases they contribute not at all. The same is true for the adverse effects of racemate drugs: the adverse effects of a racemate drug can be greater-than, less-than, or equal to one or the other enantiomer. An unusual situation arises when a drug consists of "atropisomers", stereoisomers arising because of hindered rotation about a single chemical bond. We summarize the concept of atropisomerism, and give examples.
\end{abstract}

\section{Keywords}

Atropisomer, Chirality, Pharmacotherapy, Drug Development, $\mathrm{Na}_{\mathrm{V}}$ 1.7 Inhibitor

\section{Atropisomerism}

Atropisomerism relates to chemical structures that contain at least two rings linked by a single bond. Normally, the free-energy of rotation is very low in such cases, so the rings are free to rotate about the axis of the bond. But if the rings have constituent groups sufficiently large, bulky, or otherwise repulsive, rotation can be inhibited, and create asymmetry. This situation gives rise to distinct non-interconvertible forms that are "rotational isomers" termed "atropisomers" (from the Greek for the unturning, after the eldest of the three Fates ætropoç, Atropos). The first atropisomers were identified for the compound 6,6'-Dinitro2,2'-diphenic acid (Figure 1) [1]. 


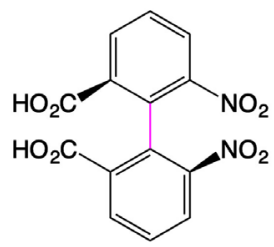<smiles>O=C(O)c1cccc([N+](=O)[O-])c1-c1c(C(=O)O)cccc1[N+](=O)[O-]</smiles><smiles>O=C(O)c1cccc(C(=O)O)c1-c1c([N+](=O)[O-])cccc1[N+](=O)[O-]</smiles><smiles>O=C(O)c1cccc([N+](=O)[O-])c1-c1c(C(=O)O)cccc1[N+](=O)[O-]</smiles>

Figure 1. 6,6'-Dinitro-2,2'-diphenic acid. The two aromatic rings are joined by a single bond, which would normally allow the rings to rotate freely around the axis of the bond. But the carboxyylic and nitro groups sterically interfere with rotation, leading to non-superimposable "atropisomers". Top: usual representation of chemical structure; Bottom: heavy lines indicate that the aromatic ring is not planar.

Some examples of naturally-occurring atropisomers that have medicinal properties and are used in pharmacotherapeutic applications include the relatively small chemical structure of the selective inhibitor of leukotriene metabolism knipholone (Figure 2) [2] obtained from the roots of the tropical ferns Kniphofia foliosa to the very large chemical structure of the antibiotic vancomycin (Figure 2) [3] obtained from the soil bacterium Amycolatopsis orientalis (Streptomyces orientalis).

\section{Relation to Drug Development}

Chirality is of well-recognized importance in medicinal chemistry and drug development because mirror-image molecules often have clinically significantly different pharmacologic properties [4] [5] [6]. The enantiomers of a chiral drug can differ in pharmacodynamics or any aspect of ADME (absorption, distribution, metabolism, or elimination). And each of the enantiomers can be pharmacologically inert, or contribute (additively, synergistically, or sub-additively) to the drug's therapeutic effect or adverse effects [4]. If one enantiomer does not significantly contribute to the desired pharmacologic effect, it has been called "isomeric ballast" [7] [8]. Widely-used drugs that benefit from the contribution of both enantiomers are the analgesic tramadol [9] [10] [11] and the antidepressant fluoxetine [12] [13] [14]. A particularly tragic example of a negative contribution of an enantiomer to a drug is thalidomide [15] [16] [17].

In the case of compounds with classical chiral centers, interconversion of enantiomers requires bond-breaking. In contrast, in the case of atropisomers, interconversion involves only rotation around a bond (Figure 3). Thus, for atropisomers, the question becomes one of relative stability of the two forms. That is, the greater the steric hindrance inhibiting free rotation, the more stable-and less interconvertible-the individual forms (Figure 4). The relevant stability for pharmacotherapeutic use has to be assessed at body conditions, since the interconversion is $\mathrm{pH}$ and temperature-dependent [18] [19]. 

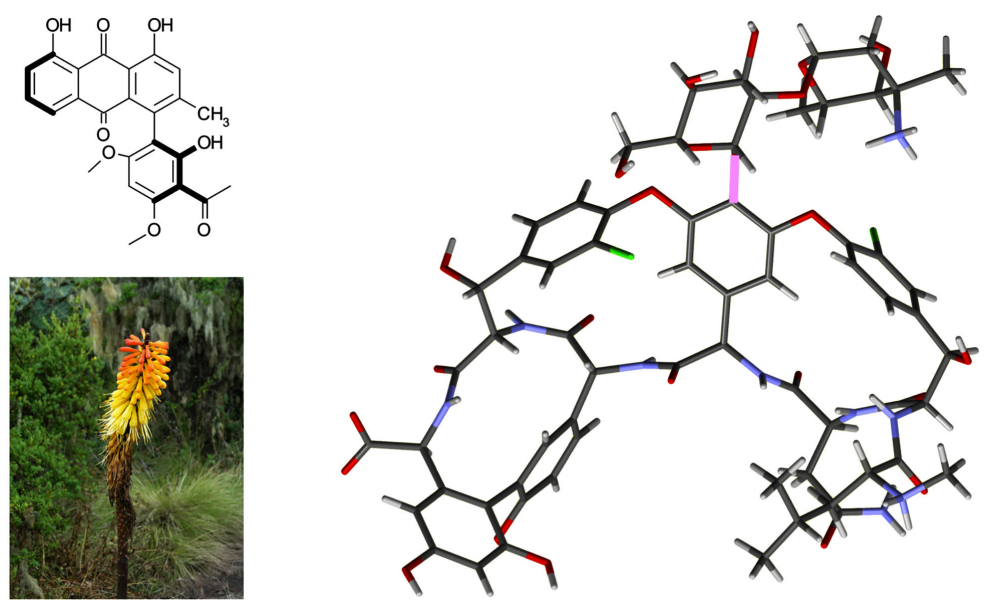

Figure 2. Left. knippholone from Kniphofia foliosa. Right. vancomycin from Amycolatopsis orientalis.

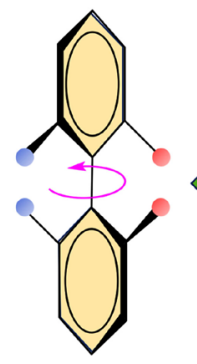

(S)

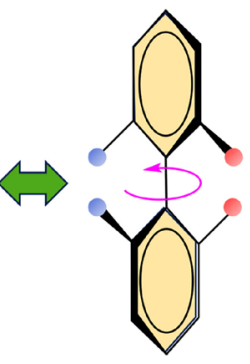

(R)

Figure 3. Rotation around the bond yields interconvertible forms (atropisomers). $(S)$ and $(R)$ are the stereochemical configurations according to the standard Cahn-Ingold-Prelog system.

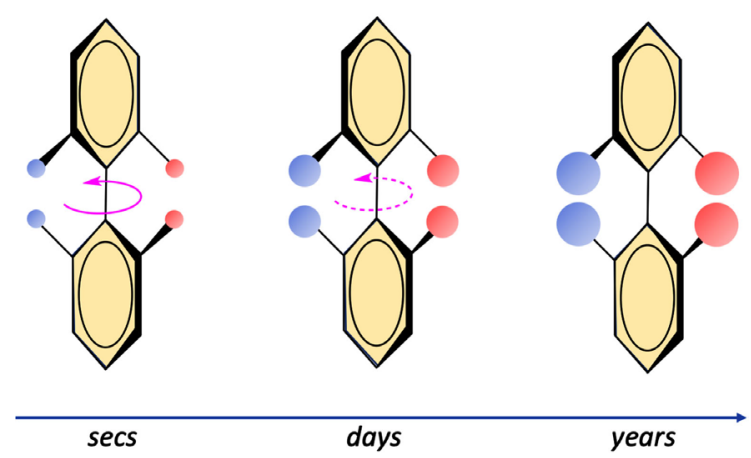

Figure 4. Greater steric hindrance increases the time of conversion from one chiral form to other. Different colors designate different constituent groups.

The complexities inherent in dealing with atropisomers in drug synthesis and development hindered enthusiasm for such compounds as drugs, but recent technical advances have spawned new interest [20]-[26] (Figure 5). As just one example, Takahashi et al. [27] introduced atropisomerism to a series of $N$-benzoylated indole derivatives of indomethacin and isolated stable atropisomers with different selectivity for cyclooxyhenase COX-1 and COX-2 isozymes. 


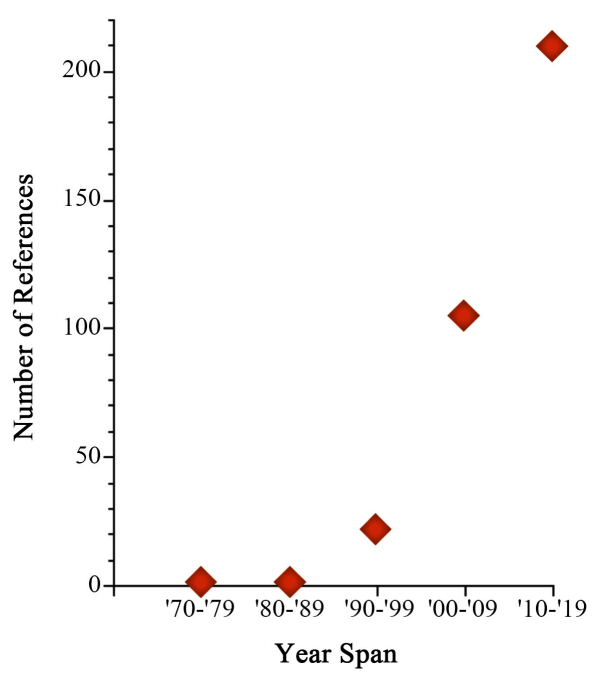

Figure 5. Number of publications listed in MedLine for the search term "atropisome(s)".

\section{Atropisomeric Nav1.7 Inhibitors}

$\mathrm{Na}_{\mathrm{V}} 1.7$ is the designation for one member of a family of sodium channels consisting of at least nine known members [28] [29]. They are proteins differentially located within certain cell membranes, and form transmembrane ion channels with selectivity for $\mathrm{Na}^{+}$ions [29]. Because of their location in dorsal root ganglia and other sites relevant to pain sensation transmission, mutations in the gene that encodes $\mathrm{Na}_{\mathrm{V}} 1.7$ in humans (SCN9A) are linked to hereditary pain disorders [30] [31] [32], and loss-of-function mutations are associated with congenital insensitivity to pain [33], the $\mathrm{Na}_{\mathrm{V}} 1.7$ type has been a favored target of analgesics drug discovery research [34] [35] [36] [37] [38] (Figure 6).

As an example, as part of a program to optimize the potency and reduce some negative ADME characteristics related to the pharmacokinetics and CYP450 metabolism of a series of selective sulfonamide $\mathrm{Na}_{\mathrm{v}} 1.7$ inhibitors [39], Graceffa et al. [40] synthesized a series of atropisomeric quinolinone sulfonamide $\mathrm{Na}_{\mathrm{V}} 1.7$ inhibitors. Several compounds had high affinity $(\mathrm{nM})$ and selectivity for $\mathrm{Na}_{\mathrm{V}} 1.7$, with improved pharmacokinetic and metabolic characteristics. One particular compound (AM-0466) showed antinociceptive activity in mice in a capsaicin-induced pain model. The analgesic pharmacologic characteristics of the atropisomer quinolone sulfonamide $\mathrm{Na}_{\mathrm{V}} 1.7$ antagonist AMG8379 (Figure 7) were reported by Kornecook et al. [41]. It demonstrated dose-related activity in several $\mathrm{Na}_{\mathrm{V}} 1.7$-dependent endpoints in vivo.

\section{Summary and Conclusions}

Atropisomerism is a less well-known type of chirality. Because the conversion of one form to the other involves rotation about a single bond, it can be relatively facile and occur in the timeframe of seconds. But, depending on the atropisomer's size and shape (steric bulk), electronic properties, and external factors 


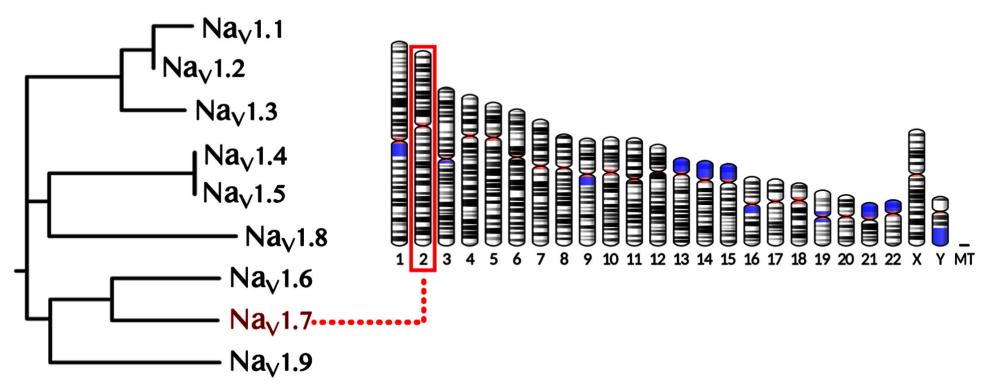

Figure 6. Putative evolutionary relationship among the $\mathrm{Na}_{\mathrm{V}} 1 . \mathrm{x}$ sodium channels and mapping to human chromosome 2. From Wikipedia.

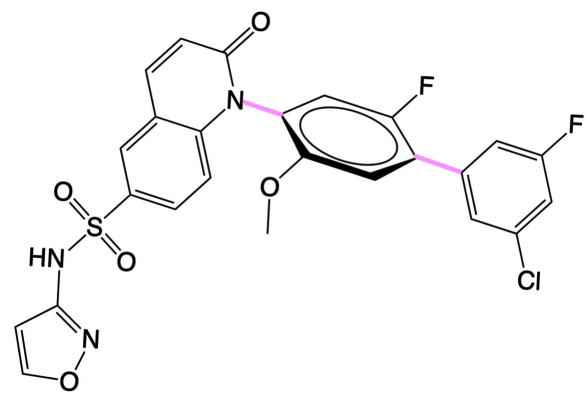

Figure 7. Chemical structure of AMG8379, an atropisomer $\mathrm{Na}_{\mathrm{V}} 1.7$ antagonist.

such as $\mathrm{pH}$ and temperature, one chiral form might not easily convert to the other form, and only do so so slowly (e.g. hours or even years) that the individual forms are essentially non-interconvertible. The recognition of, and an interest in, atropisomeric pharmacotherapeutics have increased in recent years, and several atropisomeric compounds have shown desirable properties over their non-chiral counterparts.

\section{Conflicts of Interest}

The authors declare no conflicts of interest regarding the publication of this paper.

\section{References}

[1] Christie, G.H. and Kenner, J. (1922) LXXI.-The Molecular Configurations of Polynuclear Aromatic Compounds. Part I. The Resolution of $\gamma$-6:6'-Dinitro- and 4:6:4':'6'-Tetranitro-Diphenic Acids into Optically Active Components. Journal of the Chemical Society, Transactions, 121, 614-620. https://doi.org/10.1039/CT9222100614

[2] Wube, A.A., et al. (2006) Knipholone, a Selective Inhibitor of Leukotriene Metabolism. Phytomedicine, 13, 452-456. https://doi.org/10.1016/j.phymed.2005.01.012

[3] Pfeiffer, R.R. (1981) Structural Features of Vancomycin. Reviews of Infectious Diseases, 3, S205-S209. https://doi.org/10.1093/clinids/3.Supplement_2.S205

[4] Brooks, W.H., Guida, W.C. and Daniel, K.G. (2011) The Significance of Chirality in Drug Design and Development. Current Topics in Medicinal Chemistry, 11, 760-770. https://doi.org/10.2174/156802611795165098 
[5] Nguyen, L.A., He, H. and Pham-Huy, C. (2006) Chiral Drugs: An Overview. International Journal of Biomedical Science, 2, 85-100.

[6] McConathy, J. and Owens, M.J. (2003) Stereochemistry in Drug Action. The Primary Care Companion to The Journal of Clinical Psychiatry, 5, 70-73. https://doi.org/10.4088/PCC.v05n0202

[7] Ariëns, E.J. (1991) Racemic Therapeutics-Ethical and Regulatory Aspects. European Journal of Clinical Pharmacology, 41, 89-93. https://doi.org/10.1007/BF00265897

[8] Geisslinger, G., Menzel-Soglowek, S., Beck, W.S. and Brune, K. (1993) R-Flurbiprofen: Isomeric Ballast or Active Entity of the Racemic Compound? Agents and Actions Supplements, 44, 31-36.

[9] Raffa, R.B., et al. (1992) Opioid and Nonopioid Components Independently Contribute to the Mechanism of Action of Tramadol, an 'Atypical' Opioid Analgesic. Journal of Pharmacology and Experimental Therapeutics, 260, 275-285.

[10] Raffa, R.B., et al. (1993) Complementary and Synergistic Antinociceptive Interaction between the Enantiomers of Tramadol. Journal of Pharmacology and Experimental Therapeutics, 267, 331-340.

[11] Grond, S., Meuser, T., Zech, D., Hennig, U. and Lehmann, K.A. (1995) Analgesic Efficacy and Safety of Tramadol Enantiomers in Comparison with the Racemate: A Randomised, Double-Blind Study with Gynaecological Patients Using Intravenous Patient-Controlled Analgesia. Pain, 62, 313-320.

https://doi.org/10.1016/0304-3959(94)00274-I

[12] Cârcu-Dobrin, M., et al. (2017) Enantioselective Analysis of Fluoxetine in Pharmaceutical Formulations by Capillary Zone Electrophoresis. Saudi Pharmaceutical Journal, 25, 397-403. https://doi.org/10.1016/j.jsps.2016.09.007

[13] Kim, J., Riggs, K.W. and Rurak, D.W. (2004) Stereoselective Pharmacokinetics of Fluoxetine and Norfluoxetine Enantiomers in Pregnant Sheep. Drug Metabolism \& Disposition, 32, 212-221.

[14] DeVane, C.L. and Boulton, D.W. (2002) Great Expectations in Stereochemistry: Focus on Antidepressants. CNS Spectrums, 7, 28-33. https://doi.org/10.1017/S1092852900028571

[15] Tokunaga, E., Yamamoto, T., Ito, E. and Shibata, N. (2018) Understanding the Thalidomide Chirality in Biological Processes by the Self-Disproportionation of Enantiomers. Scientific Reports, 8, 17131. https://doi.org/10.1038/s41598-018-35457-6

[16] Mori, T., et al. (2018) Structural Basis of Thalidomide Enantiomer Binding to Cereblon. Scientific Reports, 8, 1294. https://doi.org/10.1038/s41598-018-19202-7

[17] Vargesson, N. (2015) Thalidomide-Induced Teratogenesis: History and Mechanisms. Birth Defects Research Part C: Embryo Today: Reviews, 105, 140-156. https://doi.org/10.1002/bdrc.21096

[18] Toenjes, S.T. and Gustafson, J.L. (2018) Atropisomerism in Medicinal Chemistry: Challenges and Opportunities. Future Medicinal Chemistry, 10, 409-422. https://doi.org/10.4155/fmc-2017-0152

[19] Welch, C.J., et al. (2009) Factors Influencing the Interconversion of a New Class of Dibenzodiazepine Sulfonamide Atropisomers. Chirality, 21, E105-E109. https://doi.org/10.1002/chir.20785

[20] Nguyen, T. (2018) Giving Atropisomers Another Chance. Chemical \& Engineering News, 96, 22-25. https://doi.org/10.1021/cen-09633-feature1

[21] Beutner, G., et al. (2018) Adventures in Atropisomerism: Total Synthesis of a Com- 
plex Active Pharmaceutical Ingredient with Two Chirality Axes. Organic Letters, 20, 3736-3740. https://doi.org/10.1021/acs.orglett.8b01218

[22] Bai, H.Y., et al. (2019) Highly Atroposelective Synthesis of Nonbiaryl Naphthalene-1,2-Diamine N-C Atropisomers through Direct Enantioselective C-H Amination. Nature Communications, 10, 3063. https://doi.org/10.1038/s41467-019-10858-x

[23] Bonne, D. and Rodriguez, J. (2017) Enantioselective Syntheses of Atropisomers Featuring a Five-Membered Ring. Chemical Communications, 53, 12385-12393. https://doi.org/10.1039/C7CC06863H

[24] Wencel-Delord, J., Panossian, A., Leroux, F.R. and Colobert, F. (2015) Recent Advances and New Concepts for the Synthesis of Axially Stereoenriched Biaryls. Chemical Society Reviews, 44, 3418-3430. https://doi.org/10.1039/C5CS00012B

[25] LaPlante, S.R., Edwards, P.J., Fader, L.D., Jakalian, A. and Hucke, O. (2011) Revealing Atropisomer Axial Chirality in Drug Discovery. ChemMedChem, 6, 505-513. https://doi.org/10.1002/cmdc.201000485

[26] Laplante, S.R., et al. (2011) Assessing Atropisomer Axial Chirality in Drug Discovery and Development. Journal of Medicinal Chemistry, 54, 7005-7022. https://doi.org/10.1021/jm200584g

[27] Takahashi, H., et al. (2011) Atropisomerism Observed in Indometacin Derivatives. Organic Letters, 13, 760-763. https://doi.org/10.1021/ol103008d

[28] Yu, F.H. and Catterall, W.A. (2003) Overview of the Voltage-Gated Sodium Channel Family. Genome Biology, 4, 207. https://doi.org/10.1186/gb-2003-4-3-207

[29] Catterall, W.A., Goldin, A.L. and Waxman, S.G. (2005) International Union of Pharmacology. XLVII. Nomenclature and Structure-Function Relationships of Voltage-Gated Sodium Channels. Pharmacological Reviews, 57, 397-409. https://doi.org/10.1124/pr.57.4.4

[30] Lampert, A., Dib-Hajj, S.D., Tyrrell, L. and Waxman, S.G. (2006) Size Matters: Erythromelalgia Mutation $\mathrm{S} 241 \mathrm{~T}$ in $\mathrm{Na}_{\mathrm{V}} 1.7$ Alters Channel Gating. The Journal of Biological Chemistry, 281, 36029-36035. https://doi.org/10.1074/jbc.M607637200

[31] Fertleman, C.R., et al. (2006) SCN9A Mutations in Paroxysmal Extreme Pain Disorder: Allelic Variants Underlie Distinct Channel Defects and Phenotypes. Neuron, 52, 767-774. https://doi.org/10.1016/j.neuron.2006.10.006

[32] Han, C., et al. (2012) $\mathrm{Na}_{\mathrm{V}}$ 1.7-Related Small Fiber Neuropathy: Impaired Slow-Inactivation and DRG Neuron Hyperexcitability. Neurology, 78, 1635-1643. https://doi.org/10.1212/WNL.0b013e3182574f12

[33] Cox, J.J., et al. (2006) An SCN9A Channelopathy Causes Congenital Inability to Experience Pain. Nature, 444, 894-898. https://doi.org/10.1038/nature05413

[34] Goncalves, T.C., Benoit, E., Partiseti, M. and Servent, D. (2018) Corrigendum: The $\mathrm{Na}_{\mathrm{V}} 1.7$ Channel Subtype as an Antinociceptive Target for Spider Toxins in Adult Dorsal Root Ganglia Neurons. Frontiers in Pharmacology, 9, 1241. https://doi.org/10.3389/fphar.2018.01241

[35] Goncalves, T.C., Benoit, E., Partiseti, M. and Servent, D. (2018) The $\mathrm{Na}_{\mathrm{V}} 1.7$ Channel Subtype as an Antinociceptive Target for Spider Toxins in Adult Dorsal Root Ganglia Neurons. Frontiers in Pharmacology, 9, 1000. https://doi.org/10.3389/fphar.2018.01000

[36] Hameed, S. (2019) $\mathrm{Na}_{\mathrm{V}} 1.7$ and Nav1.8: Role in the Pathophysiology of Pain. Molecular Pain, 15. https://doi.org/10.1177/1744806919858801

[37] Tanaka, B.S., et al. (2017) Gain-of-Function Mutation of a Voltage-Gated Sodium 
Channel $\mathrm{Na}_{\mathrm{V}} 1.7$ Associated with Peripheral Pain and Impaired Limb Development. The Journal of Biological Chemistry, 292, 9262-9272. https://doi.org/10.1074/jbc.M117.778779

[38] Meents, J.E., et al. (2019) The Role of $\mathrm{Na}_{\mathrm{V}} 1.7$ in Human Nociceptors: Insights from Human Induced Pluripotent Stem Cell-Derived Sensory Neurons of Erythromelalgia Patients. Pain, 160, 1327-1341. https://doi.org/10.1097/j.pain.0000000000001511

[39] Weiss, M.M., et al. (2017) Sulfonamides as Selective $\mathrm{Na}_{\mathrm{V}} 1.7$ Inhibitors: Optimizing Potency and Pharmacokinetics While Mitigating Metabolic Liabilities. Journal of Medicinal Chemistry, 60, 5969-5989.

https://doi.org/10.1021/acs.jmedchem.6b01851

[40] Graceffa, R.F., et al. (2017) Sulfonamides as Selective $\mathrm{Na}_{\mathrm{V}} 1.7$ Inhibitors: Optimizing Potency, Pharmacokinetics, and Metabolic Properties to Obtain Atropisomeric Quinolinone (AM-0466) that Affords Robust in Vivo Activity. Journal of Medicinal Chemistry, 60, 5990-6017. https://doi.org/10.1021/acs.jmedchem.6b01850

[41] Kornecook, T.J., et al. (2017) Pharmacologic Characterization of AMG8379, a Potent and Selective Small Molecule Sulfonamide Antagonist of the Voltage-Gated Sodium Channel $\mathrm{Na}_{\mathrm{V}}$ 1.7. Journal of Pharmacology and Experimental Therapeutics, 362, 146-160. https://doi.org/10.1124/jpet.116.239590 